\title{
Enhancing Language Learners' Motivation: The Use of Routine Breakers with Undergraduates Learning English Linguistics
}

\author{
Rosa Muñoz-Luna, Malaga University \\ Malaga, Spain
}

Article received 26 April 2013; accepted 29 October 2013; final version received 15 December 2013

\begin{abstract}
An in-depth investigation is currently being conducted regarding English as a Second Language (ESL) learners' motivation and its relationship to academic performance; these learners are all undergraduate students in Malaga University, pursuing a degree on English Studies. As part of this in-depth study, a comparative analysis was made between two student cohorts: a control group and an experimental group; the research instrument used was a questionnaire. This instrument measured students' motivation and perceptions on the subject of English linguistics. While the control group attended their usual linguistics lessons, the experimental group learners were exposed to different activities in the middle of the lessons (the so-called routine breakers in this paper). Comparison between both groups shed some light on the issue of language learners' motivation, indicating the positive effects of attention calls and group dynamics in the classroom. Likewise, various routine breaker ideas are offered and their benefits to the learners are explained.
\end{abstract}

\section{Introduction and Research Context}

Students' success in academia has been traditionally related to learners' inner and social qualities, namely, IQ, language and mathematical skills, and degree of sociability (Kroll, 1994). From a pedagogical perspective, other factors such as classroom size, curricular topics, and ways of assessing students also have been shown to impact learners' academic achievement and outcomes; as well as the so-often neglected issue of classroom management (Tartwijk \& Hammerness, 2011). Classroom management is the appropriate use of time, space, and resources by the teacher during the lesson. An effectively organised lesson and class group is more rewarding and successful, as both students and teacher benefit from exercises conveniently carried out. 
Although effective time management in class is often ignored in the pedagogical literature, both teachers' and students' motivation and attention during the lesson are highly related to the way contents are presented in lessons (Hall \& Rodríguez, 2010). As far as learners' concentration is concerned, classroom attention spans tend to be shorter nowadays. The constant use of mobile phones and the Internet improve students' ability to search for certain solutions and information online, however these devices do not provide students opportunities to develop abstract reasoning, and as a consequence, prolonged attention on a specific task becomes harder for them. In order to keep students' focus during a theoretical class of linguistics, I propose the use of routine breakers by the teacher. Both practitioners and students need this activity change to refocus the classroom purpose clearer.

As previously stated, "learners' attention span is limited" (Hull, 1984, p. 20) and teachers will benefit from being cognizant of this fact, while endeavouring to make it work in their favour. Attention is quite often an unconscious task: even though students may be consciously paying attention to a specific object/idea, their attention can be suddenly "captured (changed) automatically by a sudden change in the environment" (Styles, 2005, p. 7). Instructors may plan for necessary attention-provoking changes, called routine breakers in this paper, which based on this study seem to be a welcome respite in a theory laden lesson.

This premise goes in synch with changes in the way languages are taught. From skill-based lessons and drills, we have moved on to communication in the field of L2 teaching (Krashen, 2008, p. 179). In this way, routine breakers bring some room for communication which is closer to real-life experiences, something learners really appreciate as it motivates them to learn.

Learning environments have recently been shown to play a decisive role in the students' emotional state, satisfaction and academic aspirations. Positive and dynamic environments render frequent and active classroom participation, regular use of the library, and more time devoted to homework (Huang, 2012). All these activities increase and strengthen the emotional binding between students and faculty, resulting in higher-scoring learners.

Along these lines, I provide some examples of how to stimulate students' attention and motivation in class. The specific research questions to be answered are: 
- How does attention affect motivation in a group of undergraduate students?

- When do attention peaks take place in a group of undergraduates?

- What are the effects of routine breakers in a group of undergraduate students?

- Which are the routine breakers that can be used at university level with language learners?

Why should one pay so much attention to motivation in the classroom? Because motivation is what controls students' focus of attention; furthermore, positive and engaged behaviour is the consequence of stimulated learners in class. A specific theoretical framework has been designed to cover these issues of motivation and attention, namely, the fact that attention spans should be alternated with a change in the students' activity. It must be noted that in this article learning is understood as emotional and active engagement with curricular input.

\section{Routine Breakers: a Pedagogical Tool to Improve Attention}

"Attention is not a monolithic construct" (Holland \& Maddux, 2010, p. 305), rather it is made of various components of complex nature; the following graph illustrates and summarises Holland and Maddux's perceptions of the learning-attention binomial:

Environment

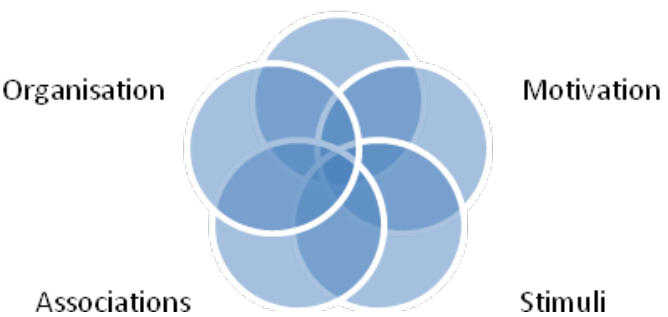

Figure 1. Components within the learning-attention binomial

Attention is linked to intrinsic motivation and learners' environments; it is also conditioned by students' goals and contexts. Regarding classroom interaction, "responses are faster to events occurring in attended locations" (Le Pelley, 2010, p. 195). Individuals paying attention to a certain stimulus are quicker to respond to it by making associations. In a language classroom this implies that emotional and semantic engagement increases, ending in a more meaningful experience. Due to the emotional 
load that is present in attentional processes, we can say that there is an element of attitude also implied (Wells \& Matthews, 1994). Students' attitudes about the class will impact their focus and strength of their attention, making it stronger or weaker depending on their motivation and engagement with the subject.

The term "attitude" has been defined as "a tendency to respond in a certain manner when confronted with certain stimuli" (Oppenheim, 1992, p. 174). It has also been explained as a mental state, which predisposes individuals positively or negatively towards an activity, and that is influenced by both internal and external factors. Attitudes can be modified throughout time depending on the stimulus the individual receives, and in foreign language education, attitudes have been always perceived as a decisive factor that can 'determine or limit students' progress in developing foreign language development" (Gardner \& Lambert, 1972, p. 3). Additionally, and in relation to classroom attention, positive attitudes have been discovered to facilitate the understanding of more abstract concepts (Mirici, 2010; Yu, 2011), holding students' attention longer.

Nowadays, there is a need for an affective pedagogical tool that can both stimulate positive attitude as well as strengthen learners' attention skills. This requirement is based on Oladejo's (1992) principle: "we cannot afford to be interested only in the attitudes of the teacher", but attention must be paid to students' emotions and feelings (p. 50). Class routine creates a sense of habituation, which is not favourable for students' attention. Habituation provokes a loss of effectiveness in attention, as students feel tired after a monotonous time lapse of theoretical teaching (Hall \& Rodríguez, 2010 , p. 44). It is also hard for teachers to keep learners' attention for more than an hour; motivation will inevitably decrease over time.

At this point, routine breakers reintroduce the idea of learning English through personal interaction and affection (Hull, 1984, p. 16), therefore bringing in the concepts of motivation and engagement. However innovative this idea might sound, the link between cognition and affect is not new: interpersonal community learning stresses this bond (Hull, 1984, p. 17), where all members of a learning community are active participants in it. Interpersonal relations enhance classroom motivation -and allow for language practice, which is so necessary in L2 learning; learners have the opportunity for interaction in routine breakers, as we describe in the following section of this paper. 
Conceptually speaking, a routine breaker is a radical change or break in the lesson being taught while the lesson is transpiring. Teachers plan and administer these routine breakers as part of their lessons. The different procedures in a routine breaker might depend on the time devoted to it in class:

- Less than 5 minute routine breakers: 1) invite students to stand up, find a partner (which could be their nearest classmate) and pose questions to each other; 2) show students some cartoons on the topic dealt with in class, with the aim of relating words and images and reformulating the concepts

- 5 to 10 minute routine breakers: 1) give students short exercises to complete and correct immediately afterwards; 2) show students some career opportunities related to topics seen in class; or 3) analyse common errors found in exam and assignments.

- 10 to 15 minute routine breakers: 1 ) invite students to move around the class and find someone else to work; 2) give students longer exercises to do and correct together; 3) take short mock exams in the class

During a lesson, the neurological activity is active when students are paying attention; however, it decreases gradually over time, being weaker when they have to focus their attention on the same issue for more than 20 minutes. For this reason, routine breakers must also bear a surprise factor to break the previous monotony, as "the more surprising a reinforcer, the more effective it is in establishing new learning" (Holland \& Maddux, 2010, p. 308). In the following section, I explain how to introduce and implement routine breakers in a class of Spanish undergraduates of English.

\section{Research Methodology}

The subjects taking part in this study were 110 undergraduate students of English Philology at Malaga University. They were divided into two groups according to when they met for class (morning and evening); the morning group $(\mathrm{N}=68)$ was the control group (herein after $\mathrm{CG}$ ), and the evening group $(\mathrm{N}=42)$ the experimental one (hereinafter EG). We are aware and want to acknowledge here the limitations of this study; further implementations will be made in bigger student groups.

Both groups (CG and EG) attended 90-minute lessons twice a week. The CG lessons consisted of lectures (theory) and application of the theory (exercises), and the EG 
lessons, in addition to theory and practice, contained some routine breakers. The results of this study showed a significant difference in learners' attention during the CG and EG lessons, as well as a higher retention rate of new concepts some days after their introduction in the EG class.

These two student groups' performances were compared for two months, during which time both groups were exposed to different teaching methodologies. EG students had a routine breaker after 40 minutes of theoretical teaching (routine breakers were always accompanied by a visual call (i.e. attention call): a video or a Prezi ${ }^{\circledR}$ presentation). After 8 weeks of controlled comparison and teaching practice, both groups were asked to complete an anonymous online test containing 5 questions about their attention, motivation, and curricular contents on the subject (see Appendix 1), in which the sole identifier was the class to which each student was ascribed.

Routine breakers were also accompanied by a change in the teacher's voice tone. Practitioners' voices change when talking about different topics; these modulations attract students' attention. Another option for changing attention focus without changing visual input is a shift in the subject matter. The routine breakers presented in this study dealt with various topics intended to address students' needs and interests; these go from ideas for students' career development and job offers, to study techniques and English syntax practice.

The following list corresponds to examples of routine breakers used with the EG for this study:

- Professional development and career prospects related to students' careers in English linguistics: brief description of the main international scholarship students can apply for, possible job opportunities in the country and abroad, postgraduate education worldwide, contact details to find more information about these topics (8-10 minutes)

- Techniques to manage stress in the academic world: tips to overcome anxiety while studying English linguistics (grammar tips, conceptual relations among the different topics), time management ideas, time management programmes and assertive academic thinking skills (psychopedagogical clues to overcome academic overload) (5 minutes) 
- Study techniques: task organisation in English linguistics subjects, revision of previous concepts, ideas of how to practise at home, resources to look at for extra practice, Gardner's multiple intelligences theory and students' sharing of personal experiences (8-10 minutes)

- Examples of English sentences taken from adverts, cartoons or TV commercials, that demonstrate the application of theoretical linguistic principles in real language use (e.g. company mottos and product slogans) (5 minutes)

- Mock exams and exam-like assignments: either in pairs, in groups or individually, students respond to exam-like questions and tasks, which help them review course contents while practising for the final exam (15 minutes)

\section{Study Results: CG and EG Answers to the Online Questionnaire}

Routine breakers are effective in both small and large classrooms. Class group size conditions the way L2 is taught and learned (Oladejo, 1992, p. 48), but routine breakers are good stimulants no matter how numerous student groups are. According to the results of this study, larger student groups (CG in this case) slowed down the learning process, making breakers more necessary to alleviate the heavy rely on contents. Students had fewer opportunities to practise L2 in those groups and to assimilate new concepts; practice was scarce and usually less monitored. In this context, routine breakers provide the perfect ground for extra and guided practice.

Regarding the level of distraction of students in class, the results in both CG and EG determined by the research questionnaires used in our study are shown in the following graphs. The numbers shown in all the graphs correspond to the amount of participants responding to each questionnaire option (blank answers are not included in the graphs). In this case, students are describing their level of concentration during class: 


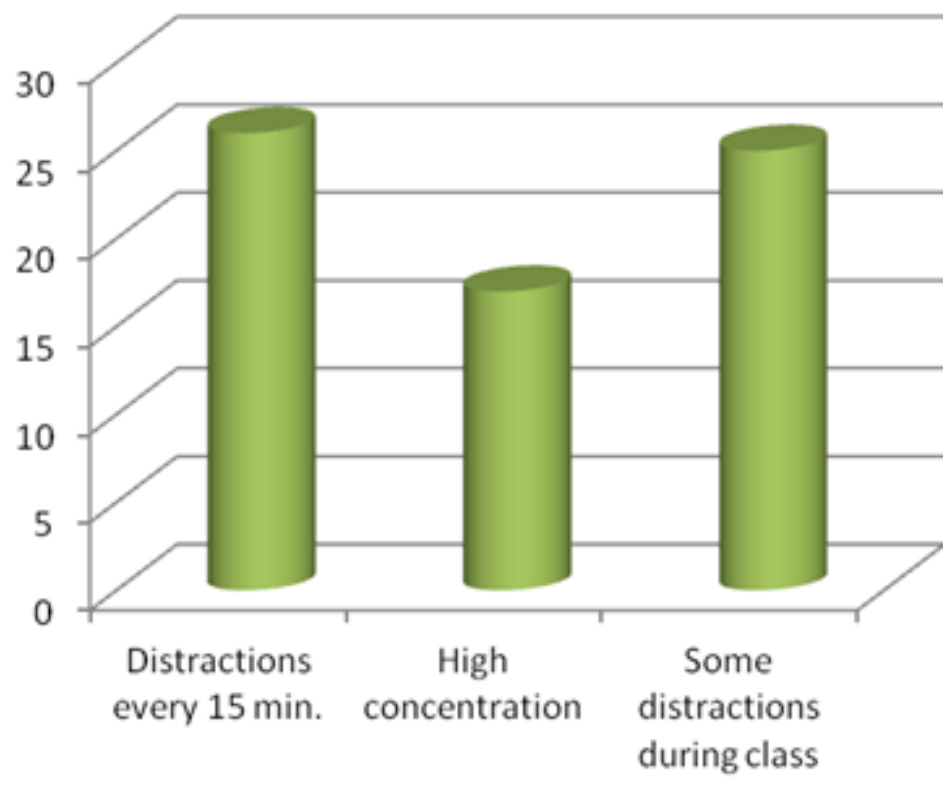

Figure 2. CG level of attention in class

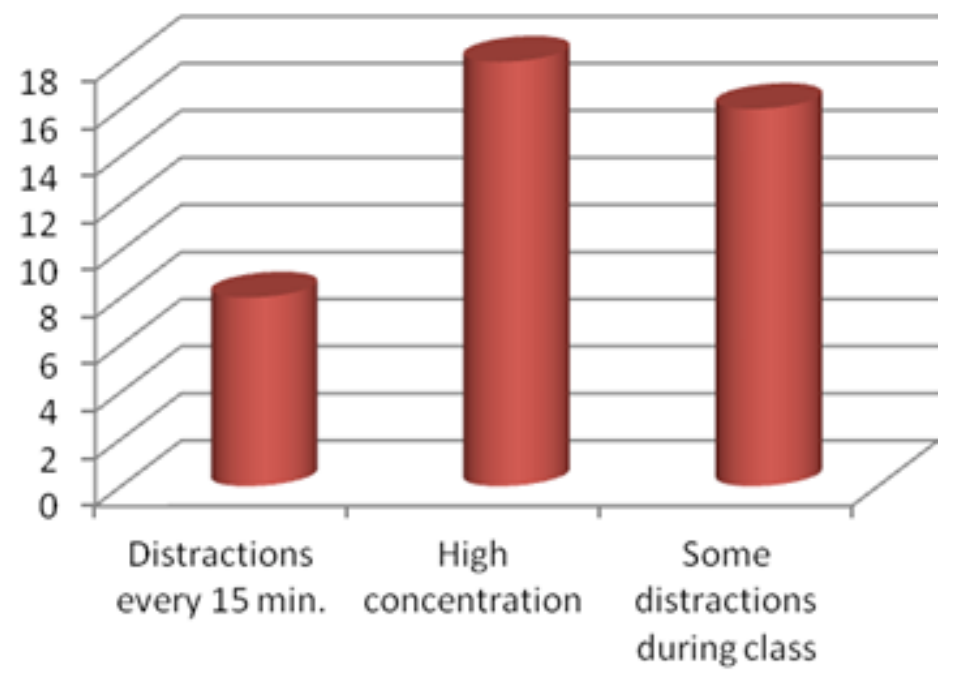

Figure 3. EG level of attention in class

As Figures 4 and 5 show, the level of attention in both student groups varies as a consequence of the use of routine breakers in the classroom. EG students develop a higher degree of concentration in class, something that their morning colleagues are replacing by constant mobile checkups. Both groups seem to have some distractions during their lessons, something we find normal in such a wide time span of 90 minutes. EG level of attention made students particularly interested in certain aspects of the 
course, such as practical applications of the theoretical notions, as the following results indicate:

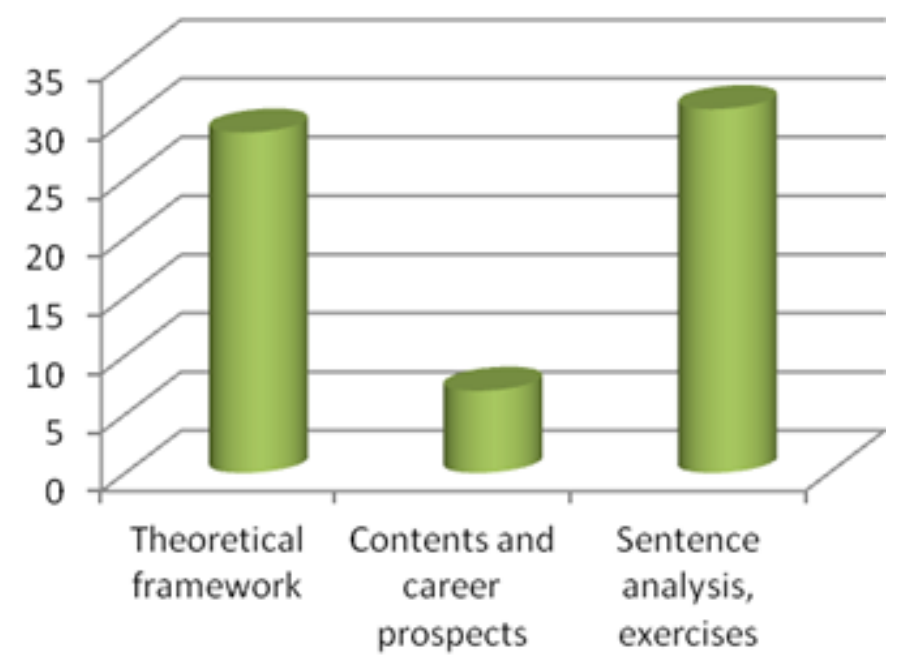

Figure 4. CG preferences regarding subject contents

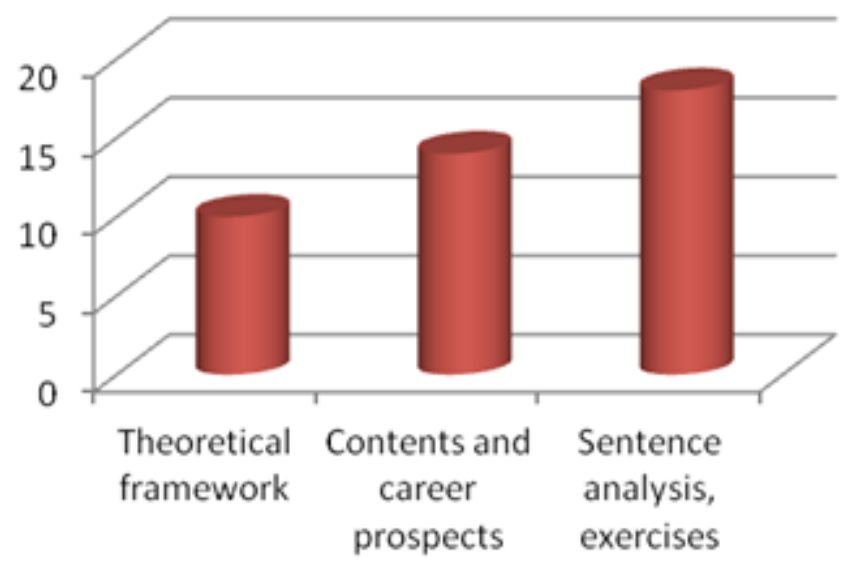

Figure 5. EG preferences regarding subject contents

The figures above indicate that $\mathrm{CG}$ students do not make associations between the subject contents and their future career prospects; instead they tend to focus on the theoretical part of the course, although they still enjoy the practical aspect of the course more. On the other hand, EG members are capable of linking subject lessons with their career development as they learn to do so in their routine breakers, i.e., they make connections between linguistics and English teaching, and between language analysis and postgraduate studies. Those associations increase learners' motivation and personal implication in classroom tasks, as we can see in the following data; these graphs reveal 
students' opinions about the course, existing a notable difference in subjects' motivation depending on the group they belong to:

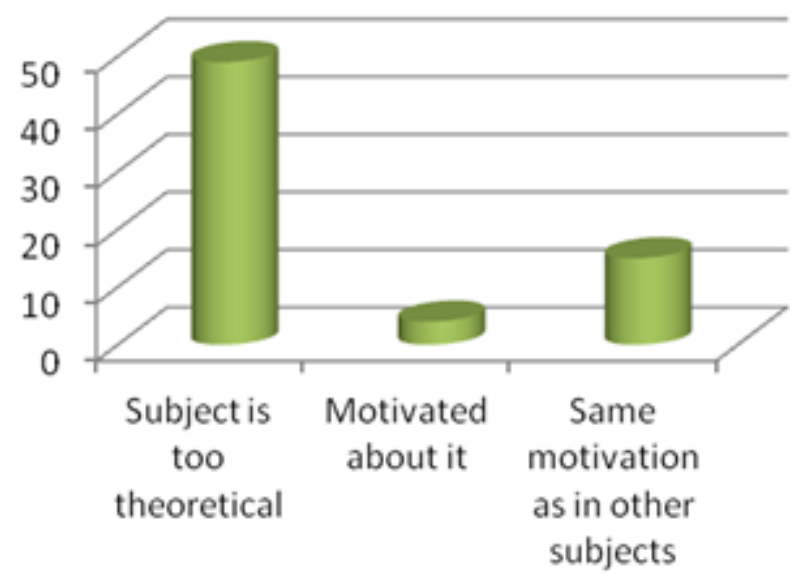

Figure 6. CG degree of motivation towards the subject

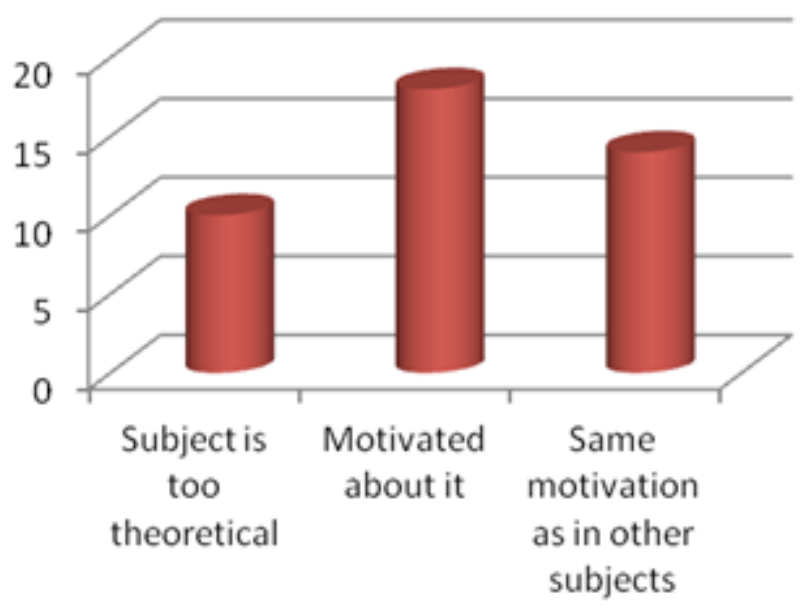

Figure 7. EG degree of motivation towards the subject

The motivational differences between both groups are outstanding: whereas CG members perceive the linguistics course as heavily theoretical (and therefore not very motivating), students in the EG are much more enthusiastic about it even though they are aware of the theoretical contents. Moreover, students' attentional flow is neither constant nor linear throughout the class time; question 4 in the questionnaire sheds some light on attention peaks and lows: 


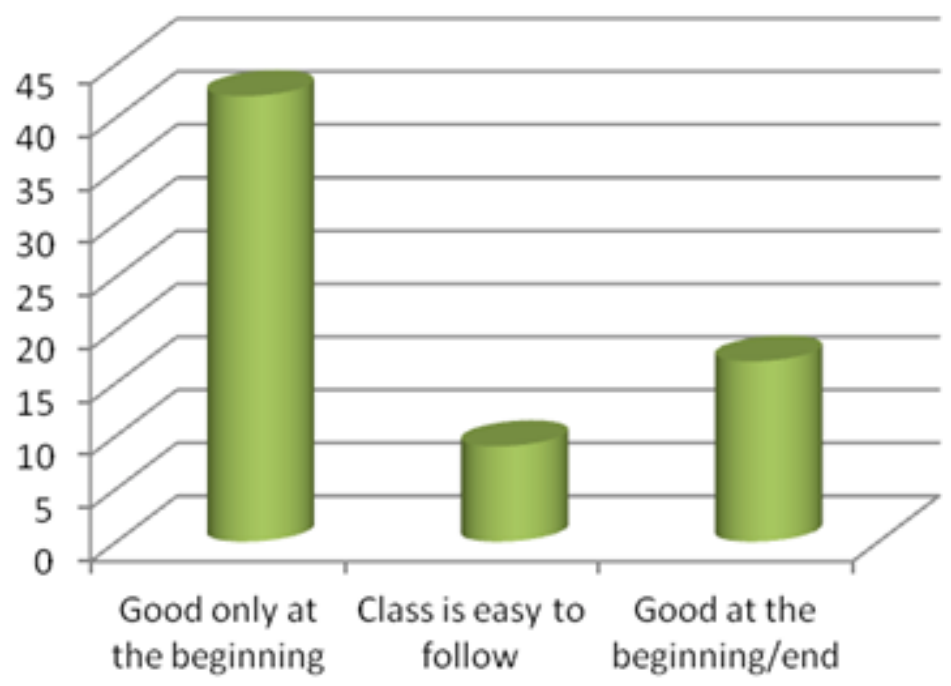

Figure 8. CG attention peaks during class

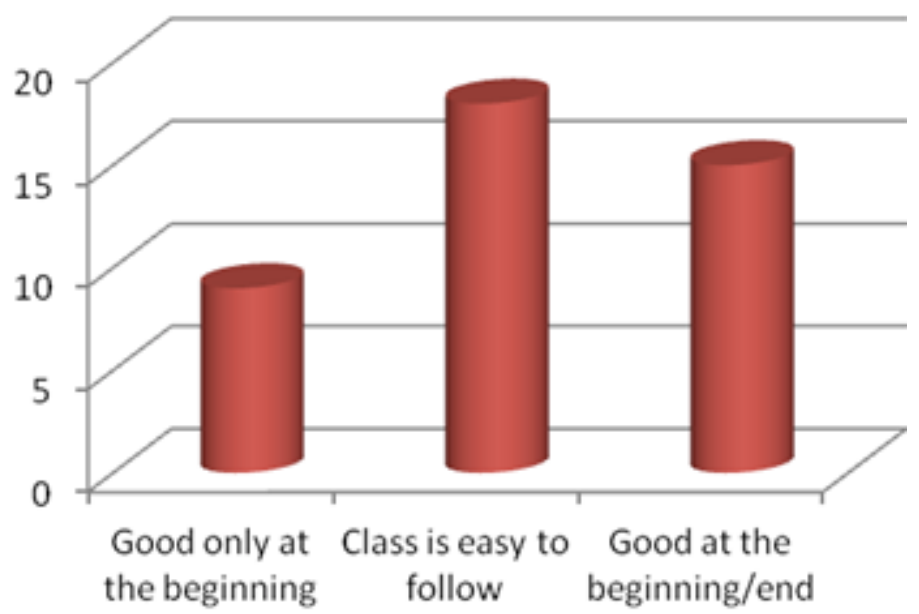

Figure 9. EG attention peaks during class

As we can see, CG students are particularly attentive at the very beginning of the lesson, but their attention skills decreases as the class progresses. That does not happen with EG students, who find these classes easy to follow on the whole. Question 5 focuses on students' perceptions of the subject of English linguistics. From a set of theoretical principles to the learning of the English semantics and grammar, learners describe the subject according to their classroom experiences. These classroom experiences include routine breakers only for the EG: 


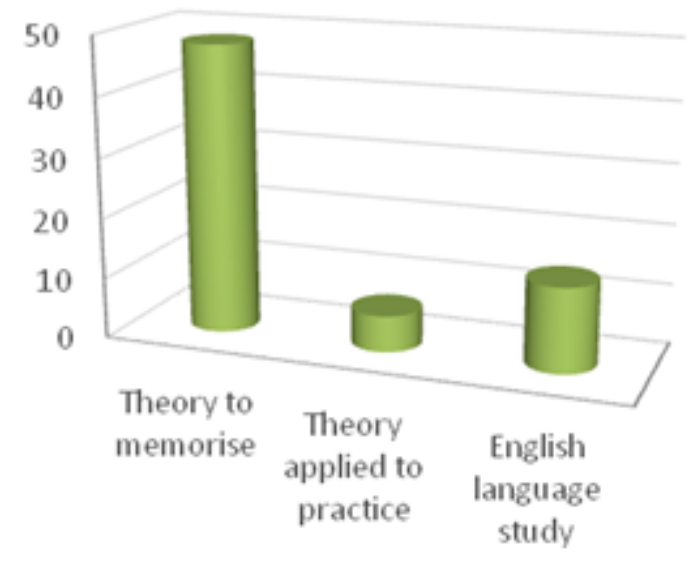

Figure 10. CG perception about the class

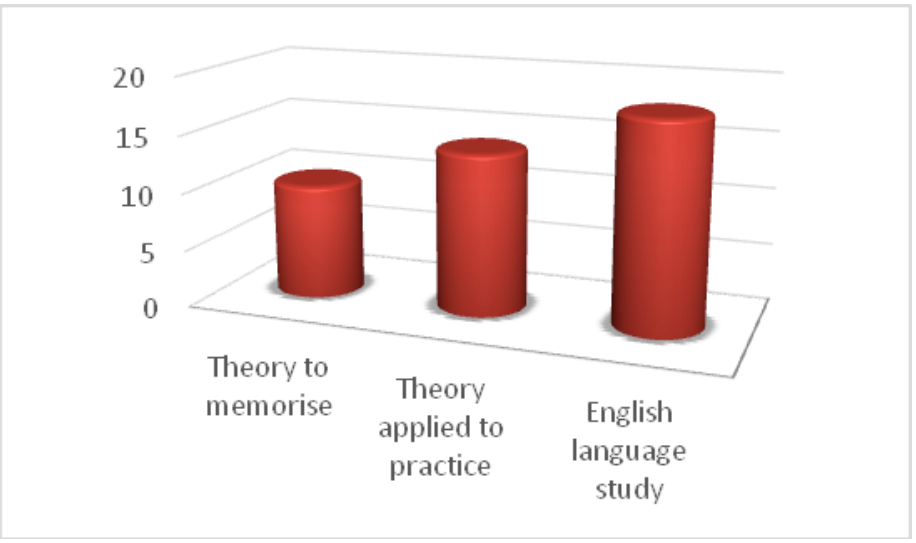

Figure 11. EG perception about the class

High-attainment writers present more positive attitudes towards the subject and towards its professional applicability. Although they can perceive some difficulty in the field of academic linguistics, they are able to overcome those problems and they can identify themselves with the subject more easily. Finally, there is a striking difference in the way both student groups approach the activities: more motivated students in the experimental group are actively engaged throughout the session, while others do not participate nor contribute so much to the lesson, with the exception of the beginning of the lesson, time in which more students reported participating. Working and playing with theoretical and practical concepts allows motivated students to remember them better. 


\section{Discussion of results}

Based on the participants' answers, I conclude that longer attention spans and good teaching are best achieved when the following variables are in place:

- fewer number of distractions in class;

- more practical applicability of contents;

- higher motivation towards the subject of linguistics;

- more frequent and stronger attention spans during the class;

- balanced theory vs. practice interface.

These variables combine and thus result in behavioural patterns and procedures, which make a linguistics session a place for academic motivation and understanding of language. High motivation implies continuous attention during the session, no need for frequent breaks and a lower number of distractions. Attention spans are longer when students find practical applications of lesson contents out of the classroom, whether as future career prospects or as practical analyses of the English language. The main consequence of this motivating environment is a more personal engagement of the student, who finds classes easier to follow. Finally, a goal of positive class dynamics is to balance theory and practice in the subject during the lesson. All this implies active participation from all the constituents of the learning community: teachers and students alike.

Transposing concepts to other fields is key to integrate them in the previous mass of knowledge structures. In this way, routine breakers provide the necessary connections between theoretical notions and previous knowledge, and also between theory and, in this case of linguistics learning, sentence practice.

Cognitive psychology explains these processes of attention and perception. This psychological branch states: "attentional selection is deemed necessary because the rest of the processing system cannot process all stimulus inputs or all response outputs simultaneously" (Styles, 2005, p. 6). In fact, visual attention in class is selective: teachers can guide students' attention towards a specific concept. Attention can be captured, called, and guided by means of visual resources. This is possible thanks to "cells in peripheral vision having the property of interrupting the ongoing processing of information" (Styles, 2005, p. 75). We can perceive routine breakers are powerful attentional stimuli. As such, they have mainly two features: 
- Intrinsic character: "attentional selection can be driven by the perceptual and emotional properties of the stimulus" (Le Pelley, 2010, p. 187);

- Extrinsic character: the concatenation with previous and later events in the session provoking attention.

The use of routine breakers in 90 minute long sessions has positive consequences on several levels:

- Psychological advantages regarding attention;

- Class dynamics changes and innovations;

- Academic result improvement.

Moreover, having session breaks had psychological advantages; in the case of our student subjects, we perceived the following psychological consequences: memory and implicit learning were enhanced without being fully aware of the subsequent effort. There was also an increased intrinsic interest for the curricular subject, as was inferred from more frequent classroom participation and question posing during the class: learners in the experimental group did not feel so embarrassed to share doubts with the teacher, and they even initiated group debate when a specific question arose. However, we also noticed something worth mentioning in relation to classroom attention: when using routine breakers with the evening group students, there was always the danger of just highlighting the anecdote. Language anecdotes and stories were often used to catch students' attention and to break the session monotonous rhythm in the routine breakers; they were useful to raise motivation and to diminish tiredness, but at the same time it was important to go beyond that, emphasising the key points behind the catching anecdote.

As far as classroom dynamics are concerned, routine breakers can also be used as contextual cues for later curricular activities. Specific exercises or sentence analyses were sometimes introduced during a routine breaker, and later on retaken during the class. Even physical dynamics seemed to be affected by routine breakers: students would move around the class, pair up, work in small groups, and therefore keep their attention towards the session.

In relation to academic results, routine breakers improve learners' performance thanks to motivation and practice improvement. These breakers are valid for all learning styles (Gardner, 1983). Whether we have visual students, intrapersonal and 
interpersonal learners, kinaesthetic students, musical pupils or abstract learning preferences, routine breakers serve as a motivating change in the classroom dynamics which awakes both students and teachers.

Periods of attention are related to cognitive and learning processes. If we alternate sequences of explicit learning with routine breaker spans, implicit learning takes place since attention and motivation are unconsciously enhanced. These complementary sequences correspond to primary and secondary tasks, respectively: routine breakers would be secondary tasks that come to complement primary curricular objectives. In fact, the purpose of routine breaking is purely attentional and motivational, as psychological support to follow the curricular lesson. Research shows that these short attention calls improve students' cognitive and mnemonic performance (Shanks, 2003, p. 14).

Associative learning is, within the field of foreign language acquisition, the way to ascribe meaning to language forms. These semantic associations come as a result of paying attention to pieces of input, which are mutually related. Analysis of participants' answers to the questionnaire seem to suggest that visual support and interactive tasks help establish these associative connections. Moreover, it is widely known that students are likely to remember a concept when they associate it to a picture, a visual map or a group activity in class.

Routine breakers are more effective if they are placed in the middle of the session, providing a break to the students at the right time. Learners in the EG had experienced the benefits of this teaching practice, and, as indicated in their answers to the questionnaire, they preferred it to traditional teaching (where interaction was not as common).

\section{Responding to the initial research questions}

As a response to our initial research questions, we made the following data interpretation: How does attention affect motivation in a group of undergraduate students? When we cross-relate Figures 8 and 9 with Figures 10 and 11 above, we find that there is a directly proportional relation between students' attention and their motivation towards the subject. While CG learners' attention peak is only at the beginning of the lesson, EG students find it easier to follow the class. The former show 
low motivation (Figure 8), whereas in Figure 9 we can see a high motivation towards the subject from EG members.

When do attention peaks take place in a group of undergraduates? As presented in figures 10 and 11, CG learners pay attention mainly at the beginning of the session, while their EG counterparts keep a constant level of interest throughout the lesson. Based on this study, we suggest that routine breakers help maintain student motivation and awareness during a 90 minute heavily theoretical lesson.

What are the effects of routine breakers in a group of undergraduate students? Our results indicate that the use of routine breakers in the classroom affects class dynamics from various perspectives; on an academic and curricular level, EG subjects preferred practical exercises in opposition to CG students. The former were open to devote classroom time to reflect upon their career prospects in relation to linguistics subjects, whereas CG learners found the subject more theoretical and made no connections between it and anything out of the class.

Routine breakers provide positive results on a psychological level as well, being students aware of their active role during the lesson. In this learning process, attention affects motivation, which also has positive consequences on students' predisposition towards the subject. In fact, lessons are deemed as practical, meaningful and contextualised by EG students, who hold a positive perception of what they are studying.

Which are the routine breakers that can be used at university level with language learners? The most frequently used breakers were those related to students' career prospects (comments and discussion), games and class dynamics on how to manage stress, tips to design an effective academic planning, and exam-like assignments in small groups, where theory and practice come together by using realworld language examples.

Based on this study, one could conclude that curricular aspects are as important as motivational and personal ones when affective engagement positively affects learning in the classroom. In this case, there is no dissociation between L2 linguistic skills and motivation, that is, both linguistic and extra-linguistic aspects go together when producing/understanding L2 messages. General personal competences such as 
attitudes and attention spans affect linguistic skills, having the former ones a strong influence on learners that should be considered when teaching.

\section{Concluding remarks}

Routine breakers should be short (between 2 and 15 minutes). Their purpose is to drastically change the teaching activity, shifting students' attention towards something different. Routine breakers can follow the academic topic of the lesson, or they may bring in something unrelated to it (e.g., students' career prospects, study techniques, or time management). These activities aim to attract students' attention by changing their role and their expectations; i.e. from passive to active roles and from listeners to doers of the action.

Regular use of routine breakers in the classroom has proven to have multifaceted impact in the classroom. As far as learning is concerned, results indicate that when a break is provided during the lesson, learners feel more motivated towards completing classroom activities, and students seem to acquire and retain new concepts better, and recall previously learned material with less difficulty. This quick activity change allows for a constant in-session motivation. On the part of the teacher, they also need to change their activity throughout long lessons. In this way, they avoid fatigue and so they will be more focused on their communicative task.

Physical advantages are also found in the use of routine breakers: physical arrangements/positions in a 90 minute class are quite fixed. Both students and teacher remain in the same position (sitting down or standing up, respectively), and that has a negative effect on the teaching-learning process. Routine breakers produce an overall muscle relaxation as both students and teachers change their positions (at least head and back positions, or even they change places with other classmates when performing small group tasks). Moreover, the positive consequences of routine breaking are mainly psychological. Motivation and attention are increased substantially, and that affects learning and students' perceptions on the subject. Consequently, academic outcomes improve

Academic scores improve as motivation ensures learners' predisposition for learning. Routine breakers combine and make use of a few items, namely: motivation, tasks, and attention calls, which indirectly enhance learning by means of breaking the 
rhythm of a normal session. These breakers, as powerful attention callers, play with the attention - learning interface. Teachers throw attentional stimuli in the class which activate the learning process. Familiar stimuli do not trigger a shift in learners' attention as much as innovative stimuli (as the breakers suggested in this article). By modifying our teaching behaviour, we are making a top-down approach aiming to modify students' perceptions as well as their content acquisition.

\section{Works Cited}

Gardner, H. (1983). Frames of mind: the theory of multiple intelligences. New York: Basic Books.

Gardner, R., \& Lambert, W. (1972). Attitudes and motivation in second-language learning. Rowley: Newbury House.

Hall, G. \& Rodríguez, G. (2010). Attentional learning. In C. Mitchell \& M. Le Pelley (Eds.) Attention and associative learning (pp. 41-70). Oxford: Oxford University Press.

Holland, P., \& Maddux, J. (2010). Brain systems of attention in associative learning. In C. Mitchell \& M. Le Pelley (Eds.) Attention and associative learning (pp. 305350). Oxford: Oxford University Press.

Huang, S. (2012). Learning environments at higher education institutions: relationships with academic aspirations and satisfaction. Learning environments research 15(3), 363-378.

Hull, P.V. (1984). Community language learning: is it a method? RELC Journal 15(2), $15-25$.

Krashen, S. (2008). Language education: past, present and future. RELC Journal 39(2), 178-187.

Kroll, S. (1994). Academic status: statements and resources. Chicago, IL: Academic status committee.

Le Pelley, M. (2010). Attention and human associative learning. In C. Mitchell \& M. Le Pelley (Eds.) Attention and associative learning (pp. 187-215). Oxford: Oxford University Press.

Mirici, I. (2010). Influence of prestudy on foreign language learning attitude. Social behaviour and personality, 38(2), 187-196.

Oladejo, J. (1992). Studies in language learning in large classes: a critical appraisal. RELC Journal 23(1), 48-61.

Oppenheim, A. (1992). Questionnaire design, interviewing and attitude measurement. Londres: Continuum.

Shanks, E. (2003). Attention and awareness in implicit sequence learning. In L. Jiménez (Ed.) Attention and implicit learning (pp. 11-42). Philadelphia: John Benjamins.

Styles, E. (2005). Attention, perception and memory: an integrated introduction. Hove / New York: Psychology Press.

Tartwijk, J., \& Hammerness, K. (2011). The neglected role of classroom management in teacher education. Teaching Education 22(2), 109-112.

Wells, A., \& Matthews, G. (1994). Attention and emotion: a clinical perspective. Hove: Lawrence Erlbaum Associates. 
Yu, M. (2011). Learning how to read situations and know what is the right thing to say or do in an L2: a study of socio-cultural competence and language transfer. Journal of Pragmatics, 43(4), 1127-1147.

Rosa Muñoz-Luna obtained an MA in TESOL from Exeter University in 2010 and an MA in English Linguistics from the University of Málaga in 2008. She completed a European PhD on L2 writing processes at the University of Málaga in 2012. Her research interests include psycholinguistic issues such as attention and motivation processes in language learning, discourse analysis and, more recently, L2 oral intonation aspects. She is a teacher at the Department of English, French and German Philology of the University of Málaga.

Email: rmluna@uma.es

\section{Appendix: Final online questionnaire questions:}

1. How easily do you get distracted in class?

a. I tend to check my mobile phone once every 15 minutes

b. I normally forget about my mobile phone in class

c. I look at my phone once or twice during class

2. What do you find particularly interesting in the subject?

a. All the theoretical framework supporting sentence analysis

b. The linking between subject contents and future career opportunities

c. Sentence analyses and exercises we have done in class

3. Describe your degree of motivation in the subject of theoretical linguistics:

a. For me, the subject is too theoretical

b. I have had a more motivating approach to this subject

c. I feel the same motivation as with the rest of my subjects

4. When do you think you can pay more attention to the teacher in class?

a. At the very beginning, then I feel tired and the class is harder to follow

b. My attention capacity goes up and down during the class, but I can easily follow the teacher

c. At the beginning of the class and at the very end I feel I can pay more attention to class contents.

5. Choose a description for this subject of English linguistics:

a. It is a set of theoretical principles to be memorised

b. It is the learning of theory to be applied to sentence analysis

c. It is the study of the English language: grammar and semantic

To cite this article:

Muñoz-Luna, R. (2014). Enhancing language learners' motivation: The use of routine breakers with undergraduates learning English linguistics. Bellaterra Journal of Teaching \& Learning Language \& Literature, 7(1), 33-51. 